\title{
Food safety knowledge, attitudes and practices among food handlers working in meat selling establishments in the City of Nairobi
}

\author{
Mathenge $\mathrm{JM}^{1}$, Gicheru $\mathrm{MM}^{1}$, Okemo $\mathrm{PO}^{2}, \mathrm{Ng}^{\prime}$ ang'a $\mathrm{PM}^{3}$, Mbaria $\mathrm{JM}^{4}$
}

\section{${ }^{1}$ Department of Animal \\ Sciences, Kenyatta \\ University, Nairobi, Kenya \\ ${ }^{2}$ Department of Medical \\ Microbiology Sciences, \\ Kenyatta University, \\ Nairobi, Kenya \\ ${ }^{3}$ Division of Vector-Borne \\ and Neglected Tropical \\ Diseases, Ministry of \\ Health, Kenya \\ ${ }^{4}$ College of Agricultural \\ and Veterinary Medicine, \\ University of Nairobi, \\ Kenya}

Corresponding author:

Mr JM Mathenge,

Department of Animal

Sciences, Kenyatta

University, P.O.

Box 43844-00100,

Nairobi, Kenya. Email.

mmathenge@ku.ac.ke

\section{Abstract}

Introduction: Food-borne diseases have been increasing in recent years with a greater impact on health and economies of developing countries. Good levels of knowledge towards food safety among food handlers and the effective practices in food handling are imperative in reducing such illnesses.

Objective: The aim of the present study was to evaluate the level of knowledge, attitudes and practices in food safety among food handlers working in meat selling and processing points within Nairobi city.

Methodology: A cross-sectional study was conducted in the City of Nairobi. Data were collected from 100 food handlers working in food establishments selling meat in the city using an interviewer administered questionnaire.

Results: Majority of the participants were male $(80.0 \%)$ and Christians $(89.0 \%)$. The median (interquartile range (IQR)) age of the participants was 30.5 (26.0-38.0) years. The respondents demonstrated above average proficiency in the assessments involving Knowledge, Attitudes and Practices (KAP). The overall KAP scores were not associated with age, gender, level of education and marital status. On the other hand, respondents who had ever attended a food handling and/or food safety course had a statistically significantly higher KAP mean score than their counterparts who had never attended (respectively, $31.5 \pm 0.2$ versus $30.3 \pm 0.3, p=0.003$ ).

Conclusion: The level of knowledge, attitude, and practice on food safety and food handling amongst the sampled food handlers were found to be favorable. Training, motivation and initiatives should be provided to encourage food handlers to sustain this positive trend in knowledge, attitude, and practices in food safety.

Key words: Knowledge, Attitudes, Practices, Food handlers, Safety

\section{Introduction}

Diseases spread through food still remains a common and persistent public health problem in developing countries resulting in appreciable morbidity and mortality. According to the World Health Organization (WHO), up to 2 million deaths attributable to food-borne illnesses occur in developing countries per year [1]. Food handlers play an important role in ensuring food safety throughout the chain of production, processing, storage and preparation [2]. A systematic review conducted by Todd et al [3] classified the factors contributing to outbreaks into; food worker error factors, bacterial proliferation factors, and important survival factors for pathogens. It is estimated $25 \%$ of the reported outbreaks can be avoided by safe food handling practices [4]. Education of food industry personnel in hygiene matters has also been recommended as a means of improving food handling practices and thus the safety of food. Documenting the levels of knowledge on food safety among the food handlers as well as their attitude and practices will pinpoint areas that require strengthening or attention in the training programme with regard to ensuring the safety of foods. The current study aimed at obtaining information on the food safety knowledge, attitudes and practices of the food handlers in the City of Nairobi. Information gathered from this study could be used by county government in strengthening current strategies aimed at enhancing safety of foods sold in various meat-eating outlets in the city.

\section{Materials and Methods}

Study design: This was a descriptive simple randomized cross sectional study.

Study site: The study was conducted in selected butcheries and a meat processing factory within Nairobi city of Kenya which has an estimated population of 3.1 million residents [5].

Study population: The study subjects comprised of food handlers working in registered food establishments selling and processing meat and meat products in the City of Nairobi. 
Data collection procedure: Pre-tested structured questionnaires were used to interview food handlers from the sampled meat processing and selling establishments. Information on demographics, food safety knowledge, attitudes and practice was collected.

Sample size and sampling approach: Computation of the sample size was done using Epi info ${ }^{\mathrm{TM}} 7.1 .3$ (Centers for Disease Control and Prevention (CDC), Atlanta). The indices used to compute the sample size were: confidence level $(95 \%)$, an error margin $(10 \%)$, a power $(80 \%)$ and a fifty percent frequency of a 50-50 chance of appropriate knowledge, attitude and practice of food hygiene by food handlers. Assuming 5\% non-responses, the sample size for the study was determined to be a hundred respondents. Five food establishments were selected randomly from a list of registered meat selling premises for inclusion in the study. The number of food handlers interviewed per establishment and by category were allocated using probability proportional to size approach. Individual participants were selected randomly using a lottery method.

Data management and analysis: Data collected were entered using Microsoft Excel ${ }^{\circledR}$ and imported to IBM SPSS Statistics ${ }^{\circledR} 21.0$ (IBM Corporation, New York) for statistical analyses. Analyses involved computation of appropriate descriptive statistics. Association between the variables was assessed by use of chi square $\left(\chi^{2}\right)$ tests. Anova and independent $t$ tests were used to test difference between means of various groups of respondents. The threshold for statistical significance will be set at $\mathrm{p}<0.05$.

Ethical issues: Ethical clearance to conduct the study was obtained from the Ethical Review Committee of Kenyatta University. Informed consent was obtained from all the study participants.

\section{Results}

Description of the respondents: One hundred respondents were enrolled in the current study majority being male $(80.0 \%)$ and Christians $(89.0 \%)$. Their median (interquartile range (IQR)) age was 30.5 (26.0-38.0). Analysis of the respondents' education showed that $36 \%$ and $34 \%$ of the sampled food handlers had attained secondary and post-secondary levels of education respectively. Five respondents $(5.0 \%)$ had no formal education. In terms of experience, most of the respondents $(74.0 \%)$ had worked for at least one year. Sixty four participants (64\%) had received some form of training on food handling and/or food safety.

Assessment of knowledge: The study participants were subjected to a set of fifteen questions aimed at assessing their knowledge on various facets of hygiene and food handling. For every question the respondent answered correctly a score was awarded or else none. Table 1 shows the item wise variation of the scores on knowledge. All respondents knew that hands should be washed before handling food and after visiting the bathroom. Additionally, an overwhelming majority of the respondents knew that insects such as cockroaches and flies might transmit food borne pathogens and raw (97.0\%) and cooked meat should be kept separately (97.0\%). In each case 95 (95.0\%) food handlers responded correctly to the following questions; 'Eating raw or half-cooked meat is highly risky for food poisoning?', 'Harmful bacteria multiply quickly at room temperature?' and 'Vegetables should be placed on higher shelf in a refrigerator than meat?'. Sixty one percent of the respondents were aware that apparently healthy food handlers might carry food borne pathogens. Further, 24 food handlers $(24.0 \%)$ were unaware that food poisoning could cause severe diseases that may result in hospitalization and sometimes death. An equal proportion of respondents were not aware that the habit of fingering the nose raises the risk of causing food poisoning.

Table 1: Responses to knowledge items

\begin{tabular}{|c|c|c|c|}
\hline No. & Attribute & $\begin{array}{c}\text { Frequency } \\
(\mathrm{n}=100)\end{array}$ & $(\%)$ \\
\hline 1 & $\begin{array}{l}\text { Hands should be washed } \\
\text { before handling food and after } \\
\text { visiting the bathroom }\end{array}$ & 100 & 100.0 \\
\hline 2 & $\begin{array}{l}\text { Food poisoning could cause severe } \\
\text { diseases that end in hospitalization } \\
\text { and sometimes death }\end{array}$ & 76 & 76.0 \\
\hline 3 & $\begin{array}{l}\text { Apparently healthy food } \\
\text { handlers might carry food } \\
\text { borne pathogens }\end{array}$ & 61 & 61.0 \\
\hline 4 & $\begin{array}{l}\text { Eating raw or half -cooked } \\
\text { meat is highly risky for food } \\
\text { poisoning }\end{array}$ & 95 & 95.0 \\
\hline 5 & $\begin{array}{l}\text { The habit of fingering the nose } \\
\text { raises the risk to cause food } \\
\text { poisoning }\end{array}$ & 76 & 76.0 \\
\hline 6 & $\begin{array}{l}\text { Food handlers with unhygienic } \\
\text { practice could be the source } \\
\text { for food contamination with } \\
\text { food poisoning pathogens }\end{array}$ & 94 & 94.0 \\
\hline 7 & $\begin{array}{l}\text { Eating covered leftover } \\
\text { cooked food, kept at room } \\
\text { temperature for more than } 6 \\
\text { hours, is at high risk to cause } \\
\text { food poisoning }\end{array}$ & 85 & 85.0 \\
\hline 8 & $\begin{array}{l}\text { Keeping food at refrigerator } \\
\text { temperature helps to prevent } \\
\text { food poisoning }\end{array}$ & 91 & 91.0 \\
\hline 9 & $\begin{array}{l}\text { Contacting ready to eat food } \\
\text { with bare hands cause food } \\
\text { contamination with food } \\
\text { poisoning pathogens }\end{array}$ & 85 & 85.0 \\
\hline 10 & $\begin{array}{l}\text { Skin infections can } \\
\text { contaminate food }\end{array}$ & 87 & 87.0 \\
\hline 11 & $\begin{array}{l}\text { The correct method for } \\
\text { thawing frozen meat is to } \\
\text { keep them overnight at room } \\
\text { temperature }\end{array}$ & 81 & 81.0 \\
\hline 12 & $\begin{array}{l}\text { Insects such as cockroaches } \\
\text { and flies might transmit food } \\
\text { borne pathogens }\end{array}$ & 99 & 99.0 \\
\hline 13 & $\begin{array}{l}\text { Harmful bacteria multiply } \\
\text { quickly at room temperature }\end{array}$ & 95 & 95.0 \\
\hline 14 & $\begin{array}{l}\text { Vegetables should be placed } \\
\text { on higher shelf in refrigerator } \\
\text { than meat }\end{array}$ & 95 & 95.0 \\
\hline 15 & $\begin{array}{l}\text { Raw and cooked meat should } \\
\text { be kept separately }\end{array}$ & 97 & 97.0 \\
\hline
\end{tabular}

$\mathrm{n}=$ Number of respondents 
Assessment of attitudes: Table 2 presents the findings on the assessment of the attitude of the food handlers. Majority of the study participants (86.7\%) either disagreed or strongly disagreed with the statement; 'Food borne outbreaks are natural life event'. The surveyed food handlers had a favourable attitude towards training on food handling and food safety with most of them $(88.0 \%)$ agreeing or strongly agreeing to the statement that; 'Learning more about food safety through training courses is important to me'. Furthermore, most respondents $(92.9 \%)$ were willing to change their food handling behaviors on realization that it was hazardous to the health of the customers and/or themselves. Only $13 \%$ of the food handlers agreed or strongly agreed that food borne outbreaks are natural life events. All the respondents were in strong agreement or agreed with the fact that sanitation and safe food handling were important part of their job responsibilities. An equal proportion agreed or strongly agreed that it was their responsibility as a food handler to ensure that meat they sold was safe. Majority of the respondents (90\%) either agreed or strongly agreed that being medically examined every six months was crucial in promoting a food handler's health and that of the customers. Further, 93\% and $97 \%$ of the food handlers, respectively, either greed or strongly agreed that they were willing to change their food handling behaviors on realization that what they were doing was incorrect and that sanitation and adequate employee hygiene can prevent food borne illness.

Table 2: Assessment of the attitude of the study participants

\begin{tabular}{|c|c|c|c|c|}
\hline No. & Attribute & No. & Yes $(\%)$ & No. $(\%)$ \\
\hline 1 & $\begin{array}{l}\text { Food borne outbreaks are } \\
\text { natural life events }\end{array}$ & 98 & 13.3 & 86.7 \\
\hline 2 & $\begin{array}{l}\text { Learning more about } \\
\text { food safety through } \\
\text { training courses is } \\
\text { important to me }\end{array}$ & 100 & 88.0 & 12.0 \\
\hline 3 & $\begin{array}{l}\text { I am willing to change } \\
\text { my food handling } \\
\text { behaviors when I know } \\
\text { they are incorrect }\end{array}$ & 99 & 92.9 & 7.1 \\
\hline 4 & $\begin{array}{l}\text { Sanitation and safe } \\
\text { food handling are an } \\
\text { important part of my job } \\
\text { responsibilities }\end{array}$ & 100 & 100.0 & 0.0 \\
\hline 5 & $\begin{array}{l}\text { It is important to } \\
\text { regularly check the } \\
\text { temperature of the } \\
\text { refrigerator }\end{array}$ & 99 & 89.9 & 10.1 \\
\hline 6 & $\begin{array}{l}\text { I believe that adequate } \\
\text { employee hygiene can } \\
\text { prevent food borne illness }\end{array}$ & 100 & 97.0 & 3.0 \\
\hline 7 & $\begin{array}{l}\text { I believe being medically } \\
\text { examined every six } \\
\text { months is important for a } \\
\text { food handler's health and } \\
\text { that of the customers }\end{array}$ & 98 & 89.8 & 10.2 \\
\hline 8 & $\begin{array}{l}\text { I think that it is my } \\
\text { responsibility as a food } \\
\text { handler to ensure that } \\
\text { meat I sell is safe }\end{array}$ & 100 & 100.0 & 0.0 \\
\hline
\end{tabular}

No. $=$ Number of respondents

East and Central Africa Medical Journal 2017; 3(1): 14-20
Assessment of practices: The outcomes on evaluation of practices amongst the enrolled food handlers are as shown in Table 3. The practice of washing hands was reportedly highly prevalent with most of the respondents always washing hands with water and soap before handling meat/ food $(94.0 \%)$ and after defecation and/or micturition (90.0\%). Moreover, $96.9 \%$ of the respondents said they always dried their hands with towel after washing them. Quite a sizeable proportion of respondents admitted to not always trimming their finger nails (13.3\%) and not cleaning the meat contact surfaces including the chopping boards always (16.0\%). Furthermore, $11.3 \%$ reportedly did not always ensure that they had valid medical licenses as they at times fail to go for the biannual medical checkups. Of the food handlers interviewed only $86.9 \%$ and $90.0 \%$ said that they always ensured that cooked meat was not kept at room temperature for more than 4 hours while only $90.0 \%$ always separated raw meat from ready to eat foods $(86.9 \%)$. All the respondents responded on the negative on inquiring whether they ate raw or halfcooked meat.

Table 3: Assessment of practices of the study participants

\begin{tabular}{|c|c|c|c|c|}
\hline \multirow{2}{*}{ No. } & \multirow{2}{*}{ Attribute } & \multirow{2}{*}{ Frequency } & \multicolumn{2}{|c|}{ Always } \\
\hline & & & No & Yes \\
\hline 1 & $\begin{array}{l}\text { Wearing protective gear } \\
\text { when handling meat }\end{array}$ & 99 & 10.1 & 89.9 \\
\hline 2 & $\begin{array}{l}\text { Wash your hands with } \\
\text { water and soap before } \\
\text { handling meat/food }\end{array}$ & 100 & 6.0 & 94.0 \\
\hline 3 & $\begin{array}{l}\text { Wash your hand with } \\
\text { water and soap after } \\
\text { defecation and/or } \\
\text { micturition }\end{array}$ & 100 & 10.0 & 90.0 \\
\hline 4 & $\begin{array}{l}\text { Drying hands after } \\
\text { washing them with towel }\end{array}$ & 98 & 3.1 & 96.9 \\
\hline 5 & $\begin{array}{l}\text { Ensuring you go for a } \\
\text { medical checkup every } \\
\text { six months }\end{array}$ & 97 & 11.3 & 88.7 \\
\hline 6 & $\begin{array}{l}\text { Checking the } \\
\text { temperature of the } \\
\text { refrigerator regularly }\end{array}$ & 93 & 8.6 & 91.4 \\
\hline 7 & $\begin{array}{l}\text { Stop working when you } \\
\text { have 'simple' ailments, } \\
\text { e.g., cold or lesions on } \\
\text { your hands }\end{array}$ & 100 & 21.0 & 79.0 \\
\hline 8 & $\begin{array}{l}\text { Trimming of finger } \\
\text { nails }\end{array}$ & 98 & 13.3 & 86.7 \\
\hline 9 & $\begin{array}{l}\text { Ensuring that cooked } \\
\text { meat is not kept at } \\
\text { room temperature for } \\
\text { more than } 4 \text { hours }\end{array}$ & 100 & 10.0 & 90.0 \\
\hline 10 & $\begin{array}{l}\text { Cleaning of meat } \\
\text { contact surfaces } \\
\text { including the chopping } \\
\text { boards, utensils etc }\end{array}$ & 100 & 16.0 & 84.0 \\
\hline 11 & $\begin{array}{l}\text { Separate raw meat from } \\
\text { ready to eat foods }\end{array}$ & 99 & 13.1 & 86.9 \\
\hline 12 & $\begin{array}{l}\text { Eat raw/half-cooked } \\
\text { meat (inside is pink) }\end{array}$ & 100 & $100.0^{*}$ & 0.0 \\
\hline
\end{tabular}


Overall KAP performance: For every correct response provided a score was awarded, else naught. Based on the 15-item knowledge evaluation assessment, the mean \pm standard deviation (sd) score was $13.0 \pm 1.0$. Examinations of the distribution of the ten-item test on attitude showed that scores ranged from five to ten with the mean $\pm \mathrm{sd}$ score being $7.4 \pm 0.8$. The practice assessment comprised of twelve items and the respondents scored a mean $\pm \mathrm{sd}$ of $10.6 \pm 1.1$. The maximum possible overall KAP score was 35 . The overall KAP mean \pm sd score for the study participants was 31.0 (1.9) with the range being 26 and 35 scores.

Association of KAP scores by selected attributes: On conducting the independent t-test, the overall KAP scores was found not to vary significantly by marital status and religion as shown in Table 4. Gender wise comparisons revealed that the mean KAP scores for men and women who were working as food handlers were similar statistically $(\mathrm{p}=0.265)$. The study participants who had one year of experience as a food handler or more performed slightly better than their counterparts who had less experience as food handlers. However, this did not reach statistical significance $(\mathrm{p}=0544)$.

The food handlers who had ever attended a food handling and/or food safety course had a statistically significantly higher KAP mean score than their counterparts who had reported that they had never attended a food handling and/or food safety course (respectively, 31.5 \pm 0.2 versus $30.3 \pm 0.3, \mathrm{p}=0.003)$. Besides, the overall KAP scores were varied significantly by the type of work the respondent was undertaking ( $\mathrm{p}=0.011$ ); processors were statistically significantly more knowledgeable than the sellers (31.5 \pm 0.2 against $30.5 \pm 0.3$ respectively).

Table 4: Variation of KAP scores by selected attributes

\begin{tabular}{lcccc}
\hline Characteristic & $\begin{array}{c}\text { Frequency } \\
(\mathrm{n}=100)\end{array}$ & Mean & $\begin{array}{c}\text { Std. } \\
\text { Error }\end{array}$ & P-value \\
\hline Marital status & & & & \\
$\quad$ Married & 69 & 30.9 & 0.2 & 0.939 \\
$\quad$ Single & 31 & 31.4 & 0.4 & \\
Gender & & & & \\
$\quad$ Male & 80 & 31.0 & 0.2 & 0.265 \\
$\quad$ Female & 20 & 31.0 & 0.4 & \\
Religion & & & & \\
$\quad$ Christian & 89 & 31.0 & 0.2 & 0.549 \\
$\quad$ Muslim & 11 & 31.4 & 0.6 & \\
Experience & & & & \\
$\quad>1$ year & 26 & 31.2 & 0.3 & 0.544 \\
$\quad \begin{array}{l}\text { 1 year } \\
\text { Ever attended a food handling and/or }\end{array}$ & 74 & 31.0 & 0.2 & \\
$\quad$ Yes & 64 & 31.5 & 0.2 & 0.003 \\
$\quad$ No & 36 & 30.3 & 0.3 & \\
Job description & & & & \\
$\quad$ Processors & 56 & 31.5 & 0.2 & 0.011 \\
$\quad$ Sellers & 44 & 30.5 & 0.3 & \\
\hline & & & & \\
\hline
\end{tabular}

Analysis of variance (ANOVA) of the overall KAP scores by age and education was also performed and the results are presented in Table 5. There was a decline in performance with age with the performance of food handlers aged above 35 years being the lowest. Nevertheless these variations by age were not statistically significant $(p=0.304)$. Similarly, overall KAP performance seemed to improve along with the level of education though not significant $(\mathrm{p}=0.241)$.

Table 5: Variation of KAP scores by selected attributes

\begin{tabular}{lcccc}
\hline Characteristic & $\begin{array}{c}\text { Frequency } \\
(\mathrm{n}=100)\end{array}$ & Mean & $\begin{array}{c}\text { Std. } \\
\text { Error }\end{array}$ & P-value \\
\hline Age category & & & & \\
(years) & & & & \\
$\quad \leq 25$ & 20 & 31.4 & 0.4 & 0.304 \\
$26-35$ & 46 & 31.2 & 0.3 & \\
$\quad>35$ & 34 & 30.6 & 0.3 & \\
Education & & & & \\
$\quad$ No formal & & & & \\
$\quad$ education/Primary & 5 & 29.6 & 0.9 & 0.241 \\
$\quad$ Secondary & 61 & 31.1 & 0.2 & \\
$\quad$ Post-secondary & 34 & 31.2 & 0.4 & \\
\hline
\end{tabular}

\section{Discussion}

The findings from the present study indicated a high level of knowledge, attitudes and practices among the food handlers. Majority of the sampled food handlers were men. The results corroborates with a study by Kasturwar and Shafee [6] where majority of respondents (62.7\%) were male. In contrast with these studies, some studies have reported a higher proportion of females [7, 8]. The difference in proportions could be attributed to the fact that the present study concentrated on food establishments dealing with animal products including butcheries thus a preference for males.

Knowledge: Overall, the food handlers' knowledge was high. This is in contrast with a survey that was performed in small and micro enterprises in South Africa, to assess food handlers' knowledge on food hygiene and the average percentage of correct answers was $46.0 \%$ [8]. In another study conducted in Ankara, Turkey, the mean food safety knowledge score of food handlers $(n=764)$ was $43.4 \% \pm 16.3 \%$ [9]. The food handlers expressed excellent knowledge in all the categories including high risk foods, food borne diseases, food storage temperatures, and sources of food contamination. Nevertheless, lower level of knowledge was demonstrated on enquiring about the proper method of thawing frozen food, where $81 \%$ of the food handlers reported that the correct method for thawing frozen meat is to keep them over- night at room temperature. Keeping meat and poultry cold while it is defrosting is essential to prevent the growth of harmful bacteria. There is greater danger of bacterial growth and food spoilage for food thawed at room temperature, hence the best way to safely thaw meat is in the refrigerator. The microwave can also be used to defrost meat more rapidly. Food may also be thawed in cold water in a sink 
or container and this must be clean [10]. The present study is in concordant with a survey done in Accra, Ghana [11]. On posing the same question to the food handlers they found that $90 \%$ of the food handlers thought that the correct method for thawing frozen meat and broiler is to keep them overnight at room temperature. A substantial proportion of the respondents (39\%) did not know that apparently healthy food handlers might carry food borne pathogens.

Practice: The food handlers' practice towards food safety and handling was high. A study done in Jordan found even higher scores in attitudes than the current study. The high mean score of food handlers in the latter study could be explained in by the differences in the study settings. The survey done in Jordan was conducted in a military hospital and the obeying the orders attitude of military workers could explain the discordance in the results between the two studies [12]. Indeed, the study reported significant differences in the mean percentage between the military and the civilian food handlers with the civilian score being significantly lower than those of the military food handlers.

The practice of washing hands was reportedly highly prevalent. Majority of the respondents always washed hands with water and soap before handling meat/food (94\%) and after defecation and/or micturition $(90 \%)$. Additionally, $97 \%$ of the respondents always dried their hands with a towel following hand washing. On the contrary, other studies showed that the extensive knowledge of the correct practices for hand hygiene do not necessarily translate into practice. For instance an observation study carried out by Green et al [13] showed that workers removed their gloves, if worn, placed their hands under running water, used soap, and dried their hands with paper or cloth towels (i.e., appropriate hand washing) in $27 \%$ of work activities. The discrepancy could be as a result of barriers in the workplace which may include time pressures and/or lack of staff, as well as structural factors, such as facilities and accessibility to supplies such as soap and towel.

Our study observed regular cleaning of meat contact surfaces, including the chopping boards and utensils was reportedly regularly done by $84 \%$ of the sampled food handlers. This is crucial step in the food establishments as it drastically reduced the risk cross contamination of food. A vast majority of the food handlers sampled from the military hospitals $(99 \%)$ in Jordan practiced proper cleaning and disinfecting procedure of premises, surfaces and utensils. Again, this could be attributed to the high levels of discipline associated with the disciplined forces. In discordance with present study, a survey carried out in Ireland showed that $21.5 \%$ of all the chefs interviewed opined that the use of disinfectants in sanitizing worktops is not an essential step [14]. Ready-to- eat foods must never be prepared using a chopping board or knife, that have been used to prepare raw meat, unless they have been washed thoroughly first [15]. In line with this, a substantial proportion of the food handlers interviewed
(87\%) said that they always ensured that they separated raw meat from ready to eat foods.

Enquiries on the storage position of a vegetable salad with respect to meat, most of the study participants (95\%) knew the vegetables were to be placed on the higher shelf in a refrigerator than meat. This ensures that contamination does not arise from the drips of the meat. An almost similar proportion (92\%) was reported in a study conducted in the united States of America (USA) by the Environmental Health Specialists Network (EHSNet), a network of environmental health specialists focused on the investigation of contributing factors to food borne illness, including food preparation practices and hand washing practices [13]. On the other hand, research involving food handlers working in food businesses in Accra, Ghana, found that $23.8 \%$ of the respondents reported that they would place the salad and the meat side by side. Besides, $4.8 \%$ were not certain where to place the vegetable salad [12].

A sizeable proportion of the respondents $(21 \%)$ reported not stopping working when they had 'simple' illnesses such as cold or lesions on their hands. A handto mouth existence prevails for most food handlers, their families, and the greater consideration to loss of income if they do stop working may perhaps override the effect of knowledge. Additionally, some food handlers who consciously overlook the safety risks associated with food handling during cases of ailments may perhaps believe that the risks are outweighed by their culinary prowess or that they have sufficient knowledge and experience with foods to control the degree of risk. These lines of reasoning have been cited by some studies as justifications used by food handlers who were identified as a cause of food borne diseases by asking short cuts in food handling to the detriment of food wholesomeness $[16,17]$.

Attitudes: The food handlers' attitudes towards food safety were found to be favourable which is in concordance with the findings from a survey by Sharif et al [12] where the mean score for the practice assessment was high (90\%). The surveyed food handlers had a favourable attitude towards training on food handling and food safety with most of them $(88.0 \%)$ reporting that learning more about food safety was important to them. Research done in Malaysia reported similar findings among food handlers at a residential college and canteen with a majority of the food handlers $(72.3 \%)$ stating to have learned more about food hygiene [18]. All the respondents in the current study were of the opinion that it was their responsibility to ensure that the meat they sold was safe. Further, the study reported that only $77 \%$ of the food handlers stated safe food handling was an important part of their job responsibilities was imperative for them [18].

Association of KAP scores by selected attributes: In the present study, the overall KAP scores did not significantly differ among the various categories of marital status and religion. The overall mean KAP scores for men and women were similar statistically $(\mathrm{p}=0.265)$. This is in 
discordance with a survey done in hospitals in Jordan where females had a higher mean KAP percentage score as compared to their male counterparts [13]. Moreover, a recent study by Sanlier and Konaklioglu [19] found a statistically significant difference between male and female participants on the overall KAP scores.

The study participants who had one year of experience as food handlers or more performed slightly better than their counterparts who had less experience as food handlers. However, this did not reach statistical significance $(p=0544)$. Though there was an upward trend in the overall KAP scores by levels of education these association of education and overall KAP scores was not significant. Conversely, a survey involving military hospital food handlers, the overall KAP scores were significantly $(\mathrm{P}<0.05)$ affected by the levels of education, where the average scores increased with the education level [13]. No statistically significant difference was found between participants of different experience levels just like in the study by Green et al [13]. Another study by sharif [12] also found that the educational level of respondents did not influence respondents' knowledge and practice of food hygiene. Age was not significantly associated with the overall KAP scores. The overall KAP scores varied significantly by the type of work the respondent was undertaking $(\mathrm{p}=0.011)$; meat processors were statistically significantly more knowledgeable than the respondents who were involved in serving the meat to the customers (sellers). The food handlers who had ever attended a food handling and /or food safety course had a statistically significantly higher KAP mean score than their counterparts who had reported that they had never attended a food handling and/or food safety course. This adds to the evidence on the positive impact of education on food safety.

\section{Conclusions and Recommendations}

This investigation provides valuable information about the level of knowledge, attitude, and practice in food safety of food handlers working in meat selling establishments in the City of Nairobi. Generally, it was observed that respondents had a satisfactory level of knowledge of food safety as well as a favourable attitude. Majority of the respondents exhibited above average practices in handling of foods, which is commendable. Training, motivation and initiatives should be provided to encourage food handlers to sustain this positive trend.

\section{Acknowledgements}

To the Government of Kenya, Ministry of Education, Science and Technology through National Commission for Science, Technology and Innovation grant (NACOSTI) for funding the project. NCST $/ 5 / 003 / 3^{\text {rd }}$ CALL PhD/170.

\section{Conflict of interest statement}

No conflict of interest exist between the authors or institutions with other third parties

\section{References}

1. World Health Organization. Food safety and food borne illness. Geneva: WHO; 2007.

2. Udgiri R and Yadavnnavar MC. Knowledge and food hygiene practices among food handlers employed in food establishments of Bijapur City. Indian J Pub Hlth. 2009; 53: 240-241.

3. Todd EC, Greig JD, Bartleson CA and Michaels BS. Outbreaks where food workers have been implicated in the spread of food borne disease, Part 3. Factors contributing to outbreaks and description of outbreak categories. J Food Prot. 2007; 70 (9): 2199-2217.

4. Haapala I and Probart C. Food safety knowledge, perceptions and behaviours among middle school students. J Nutr Educ Behav. 2004; 36(2): 71-76.

5. Kenya National Bureau of Statistics (KNBS). 2009 Kenyan Population and Housing Census Report. Nairobi: KNBS. 2010.

6. Kasturwar NB and Shafee M. Knowledge, practices and prevalence of MRSA among food handlers. Int J Biol Med Res. 2011; 2(4): 889-894.

7. JevŠnik M, Hlebec V and Raspor P. Food safety knowledge and practices among food handlers in Slovenia. J Food Cont. 2007; 19(12): 1107-1118.

8. Marais M, Conradie N and Labadarios D. Small and micro enterprises - aspects of knowledge, attitudes and practices of Managers' Hospital, Western Cape. South Afr J Clin Nutr. 2007; 20(2): 50-61.

9. Çakiroglu FP and Uçar A. Employees' perception of hygiene in the catering industry in Ankara (Turkey). Food Cont. 2008; 19(1): 9-15.

10. Outagamie County Health and Human Services, Public Health Division. Proper Thawing and Preparation Practices, 2010. http://www. co.outagamie.wi.us/PublicHealth Accessed on January 2, 2013.

11. Annor AG and Baiden AE. Evaluation of food hygiene knowledge attitudes and practices of food handlers in food businesses in Accra, Ghana. Food Nutr Sci. 2011; 2: 830-833.

12. Sharif L, Obaidat MM and Al-Dalalah M. Food hygiene knowledge, attitudes and practices of the food handlers in the Military Hospitals. Food Nutr Sci. 2013; 4: 241-251.

13. Green L, Selman C, Radke V, Ripley D, Mack J, et al. Food worker hand washing practices: an observational study. J Food Prot. 2006; 69(10): 2417-2423.

14. Bolton DJ, Meally A, Blair IS, McDowell DA and Cowan C. Food safety knowledge of head chefs and catering managers in Ireland. Food Cont. 2008. 19(3): 291-300. 
15. Garbutt J. Essentials of food microbiology. Hodder Headline Group, London, 1997; 116-170.

16. Klontz K, Timbo B, Fein S and Levy A. Prevalence of selected food consumption and preparation behaviours in the United States. J Food Prot 1995; 58:1405-1411.

17. Azanza VPM, Gatchalian FC and Ortega PM. Food safety knowledge and practices of street food vendors in a Philippines university campus. Int $J$ Food Sci Nutr. 2000; 51: 235-246.
18. Nee OS and Sani AN. Assessment of Knowledge, Attitudes and Practices (KAP) among food handlers at residential colleges and canteen regarding food safety. Sains Malay. 2011; 40(4): 403-410.

19. Sanlier N and Konaklioglu E. Food safety knowledge, attitude and food handling practices of students. Br Food J. 2012; 114(4): 469 - 480. 